sFRP-mediated Wnt sequestration as a potential therapeutic target for Alzheimer's

disease

Sudha Warrier*1,2 ${ }^{*}$ Raja Marimuthu ${ }^{3}$, Sreeja Sekhar ${ }^{1}$, G. Bhuvanalakshmi ${ }^{1}$, Frank Arfuso $^{4,5}$, Anjan Kumar Das ${ }^{6}$, Ramesh Bhonde ${ }^{1}$, Ralph Martins ${ }^{2,7,8}$ and Arun

\title{
Dharmarajan $^{4}$
}

1) Division of Cancer Stem Cells and Cardiovascular Regeneration, Manipal Institute of Regenerative Medicine, Manipal University, Bangalore - 560 065, India

2) School of Biomedical Sciences, Curtin Health Innovation Research Institute, Curtin University, Perth, Western Australia, 6845

3) Department of Orthopedics, Sree Balaji Medical College and Hospital, Chromepet Chennai 600044, India

4) Stem Cell and Cancer Biology Laboratory, School of Biomedical Sciences, Curtin Health Innovation Research Institute, Curtin University, Perth, Western Australia, 6845

5) School of Anatomy, Physiology and Human Biology, Faculty of Science, The University of Western Australia, 35 Stirling Highway, Crawley, Western Australia, 6009

${ }^{6)}$ Department of Surgery, Taylor's University School of Medicine, Selangor, Malaysia

7) Centre of Excellence for Alzheimer's Disease Research and Care, School of Medical

Sciences, Edith Cowan University, Joondalup, Western Australia, Australia, 6027;

8) Sir James McCusker Alzheimer's disease Research Unit, School of Psychiatry and Clinical Neurosciences, University of Western Australia, Crawley, Western Australia, Australia, 6009

* Corresponding author

Email: sudha.warrier@manipal.edu; sudha.warrier@gmail.com 


\begin{abstract}
The extracellular ligand, Wnt, and its receptors are involved in signal transduction and play an important role in axis formation and neural development. In neurodegenerative disorders such as Alzheimer's disease (AD), a decrease of the intracellular Wnt effector, $\beta$-catenin, has been linked to amyloid- $\beta$-peptide-induced neurotoxicity. Despite this knowledge, targeting Wnt inhibitors as potential biomarkers has not been explored, and harnessing Wnt activators as therapeutic candidates remains largely not investigated. A wide acting family of Wnt mediators, secreted frizzled-related proteins (sFRPs), has not been probed so far as molecular indicators of disease occurrence and progression of Alzheimer's. Unlike the effect of the Dickkopf (DKK) family of Wnt antagonists on AD, the sFRP molecules have a more pleiotropic impact on the Wnt signaling cascade and probably have a far-reaching involvement in neurodegeneration. The role of sFRPs has been poorly described in AD, and in this review, we analyze the present status of the role of sFRPs on neurodegeneration, their likely involvement, and potential implications in treatment modalities of $\mathrm{AD}$. This information would provide valuable clues for the development of potential therapeutic targets for aberrant neurodegenerative disorders.
\end{abstract}

\title{
Keywords
}

Alzheimer's disease, Wnt, sFRP, neurodegeneration 


\section{Introduction}

Neurodegenerative diseases represent a diverse spectrum of neuronal disorders with progressive dysfunctions in the nervous system. Pathologically, they are identified by the presence of disease-specific protein aggregations and misfoldings in specific regions of the brain (Jucker \& Walker, 2013). Although several neurological disorders have been identified, attention has been given to only a handful, including Alzheimer's disease (AD), Parkinson's disease (PD), Huntington's disease, and amyotrophic lateral sclerosis (Ross \& Poirier, 2004). The prevalence and incidence of these diseases increase with age (Melo et al., 2011), and reaches a peak well before the maximum lifespan. For instance, AD is the 5th leading cause of death globally for those aged 65 and older. An increase in incidence of $40 \%$ of AD has been reported worldwide and is predicted to rise dramatically to one new case diagnosed every 33 seconds, which is projected to lead to around one million new cases per year by 2050 (http://www.alz.org/facts/).

Clinically, AD is characterized by the gradual decline of neuro-cognitive functions (Gouras et al., 2010). The hallmark identification of $\beta$-amyloid (A $\beta$ ) deposits and neuro-fibrillary tangles (NFTs), formed by hyperphosphorylated tau protein in the sub-cortical regions of the brain (as reported in several studies Armstrong, 2011; Ittner and Götz, 2011; Blennow et al., 2006)), correlates with the synaptic dysfunctions and massive neuronal death observed in $A D$ (Fuentealba et al., 2004). The A $\beta$ deposition also results in the activation of proinflammatory cytokines primarily in the glial cells (Lindberg et al., 2005), initiation of the complement cascade (Aisen, 1997), and the induction of pro-inflammatory enzymes such as inducible nitric oxide synthase and cyclooxygenase-2; these factors further contribute to neuronal dysfunction and cell death (Brown and Bal-Price, 2003). The key focus of current $\mathrm{AD}$ research is on the underlying disease mechanisms, and a number of studies have 
been conducted globally to identify the potential biomarkers for this disease.

\section{Wnt signaling in AD}

Although the underlying molecular map of $\mathrm{AD}$ remains elusive, impaired Wnt signaling events are well known to promote AD pathogenesis (Inestrosa and Toledo, 2008). Wnts (Wingless) are a family of 19 members of secreted lipoglycoproteins that are multifunctional in nature (Willert and Nusse, 2012). The Wnt pathways are crucial in cell fate determination during animal development (Martin and Kimelman, 2012) and are known to regulate many developmental events in the nervous system, including the maintenance of synapses during brain development (van Amerongen and Nusse, 2009; Inestrosa and Varela- Nallar, 2014) and also in dorsal-ventral patterning in the forebrain (Harrison-Uy and Pleasure, 2012; Quinlan et al., 2009). Furthermore, ablation of Wnt variants in neuro-degenerative diseases has been reported to result in severe midbrain damage and hippocampus dysfunction (Arenas, 2014; Varela-Nallar and Inestrosa, 2013). Different mechanisms of Wnt signaling have been identified; namely, the ß-catenin dependent and ß-catenin independent pathways. The Wnt/ßcatenin pathway has been most extensively studied in neurodegeneration, especially during AD progression (Wan et al., 2014; Godoy et al., 2014). In this pathway, in the presence of Wnt ligands, signals are transduced to the nucleus via ß-catenin through the interaction of Wnt with a 7-transmembrane receptor complex, the frizzled receptor (FZD), and a coreceptor corresponding to the low density lipoprotein receptor-related protein 5/6 (LRP 5/6) membrane protein, which leads to the activation of dishevelled (DVL) (MacDonald and He, 2012; Esteve et al., 2011).

These events stabilize intracellular $ß$-catenin through the axin complex, which is composed of axin, the tumor suppressor adenomatous polyposis coli gene product (APC), and glycogen 
synthase kinase 3 beta (GSK3ß), thereby preventing its phosphorylation and ubiquitin mediated degradation (Fig 1). It has been reported that, in response to depolarization, the maintenance of intracellular ß-catenin levels is crucial in regulating neuronal homeostasis and synaptic modulations (Murase et al., 2002). Depleted levels of ß-catenin have been correlated with synaptic loss and A $\beta$ deposition (Chen and Bodles, 2007), and have been identified as key factors prior to the onset of neuronal death in many neurodegenerative diseases including AD. The ß-catenin-independent pathway of Wnt signaling has two arms: the Wnt/planar cell polarity (PCP) pathway and the Wnt/Ca ${ }^{2+}$ signaling pathway. In the $\mathrm{Wnt} / \mathrm{Ca}^{2+}$ pathway, Wnts binds to FZD resulting in stimulation of heterotrimeric $\mathrm{G}$ proteins, which further activates phospholipase $\mathrm{C}$. This leads to increased $\mathrm{Ca}^{2+}$ release and activates two kinases: $\mathrm{Ca}^{2+}$-calmodulin dependent protein kinase-II and protein kinase-C. This, in turn, stimulates transcription factors such as cAMP response element-binding protein- 1 . In the PCP pathway, Wnt proteins bind to FZD, which activates small GTP-binding proteins Rho and Rac and jun N-terminal kinase via DVL. This interaction results in cytoskeletal regulation and involves polarized cell shape changes and migration (Fig 1).

Wnt/ß-catenin signaling plays a crucial role in embryonic development of most tissues and organs of the body (van Amerongen and Nusse, 2009), and it is also important in the adult organisms, where it maintains hair, skin (Alonso and Fuchs, 2003), intestinal health, and hematopoiesis (Malhotra and Kincade, 2009). Aberrant regulation of ß-catenin levels and the ß-catenin signaling pathway have been associated with the onset of fibrosis and metabolic disease, as well as many cancers including lung, pancreas, breast, and colorectal cancers (Paul and Dey, 2008; Kahn, 2014). The Wnt/ß-catenin dependent pathway has also been extensively studied in neurodegenerative diseases, especially with respect to its involvement in $\mathrm{AD}$ progression. For example, studies on $ß$-catenin in neuronal cells have reported that neural depolarization induces $ß$-catenin redistribution from dendritic shafts into spines, where 
it interacts with cadherin to influence synaptic size and strength (Murase et al., 2002); thus, the maintenance of intracellular ß-catenin levels is crucial in the regulation of neuronal homeostasis and synaptic modulations. It has also been shown that depletion of ß-catenin levels correlates with synaptic loss and $\mathrm{A} \beta$ deposition (Inestrosa and Arenas, 2010).Furthermore, a deficiency in LRP6-mediated Wnt signaling in an AD transgenic mouse model led to greater amyloid deposition due to greater $\mathrm{A} \beta$ production; and deletion of the LRP6 gene in mice forebrain neurons led to age-dependent deficits in synapse integrity as well as memory deficits (Liu et al., 2014).

Many studies have investigated the relationship between components of the Wnt/ß-catenin signaling pathway and AD-related proteins. For example, the amyloid precursor protein (APP) intracellular domain (AICD), which is present in higher levels in $A D$, has been shown to bind to GSK3$\beta$, activating it and thereby reducing $\beta$-catenin levels. Another very pertinent observation showing a direct link between amyloid- $\beta$ and Wnt signaling indicated that amyloid- $\beta$ binds to the FZD cysteine-rich domain in close proximity to the Wnt-binding site and inhibits the Wnt $\beta$-catenin signaling pathway (Magdesian et al., 2008). In AICDtransgenic mice (Ryan and Pimplikar, 2005), studies found hyper-phosphorylation and aggregation of tau, neurodegeneration, and deficits in working memory that could be prevented by treatment with lithium chloride, a GSK3 $\beta$ inhibitor (Ghosal et al., 2009). However, the AICD-Wnt pathway relationship needs further study, as AICD has also been shown to bind to $\beta$-catenin (Zhou et al., 2011), and some neuronal studies have found GSK3 $\beta$ activation causes neurite retraction (Sanchez et al., 2001). AICD-stimulated GSK3 $\beta$ has resulted in neurite outgrowth in the PC12 and N2A neuronal cell lines as well as in primary neurons (Zhou et al., 2011). The AICD pathway also should be investigated further as it appears to be able to contribute to $\mathrm{AD}$ pathology independently of $\mathrm{A} \beta$. Another controversial link between $\mathrm{AICD}$ and $\mathrm{AD}$ involves neprilysin (NEP), a major $\mathrm{A} \beta$-degrading enzyme; 
although some previous studies have not agreed with these findings, a recent comprehensive study has found NEP expression to be dependent on AICD levels in several transgenic AD mouse models as well as in cell culture models (Grimm et al., 2015). In recent years, GSK3 $\beta$, being a key modulator of the Wnt $\beta$-catenin pathway, has emerged as one of the most relevant targets for AD treatment (Martinez and Perez, 2008). Lithium chloride (LiCl), a classic inhibitor of GSK3 $\beta$, has been shown to prevent neurotoxicity by reducing amyloid- $\beta$ production in a mouse model of $\mathrm{AD}$ (Phiel et al., 2003). LiCl has also been reported to inhibit amyloid- $ß$ induced synaptic degeneration in elderly $\mathrm{AD}$ patients with bipolar disorders (Valvezan and Klein, 2012). An increasing number of novel GSK3 $\beta$ inhibitors, which are both ATP-competitive and non-ATP-competitive, have been developed; particularly promising are the non-ATP-competitive GSK3 $\beta$ inhibitors, since they are more selective and less toxic (King et al., 2014), examples of which being L803-mts (Plotkin et al., 2003; Kaidanovich-Beilin et al., 2004) and VP0.7 (Palomo et al., 2011). The typical ATPcompetitive GSK3 inhibitors include indirubin (Leclerc et al., 2001), paullone compounds (Leost et al., 2000), SB415286 and SB216763 (Coghlan et al., 2000), and AR-A014418 (Bhat et al., 2003). Similarly, it has been shown that bromoindirubin-30-oxime (6-BIO), another GSK3ß inhibitor, was able to reduce amyloid- $§$ formation and prevent neuronal apoptosis (Silva-Alvarez et al., 2013).

Wnt signaling has also been shown to influence levels of $\beta$-amyloid precursor protein cleaving enzyme-1 (BACE1), as chromatin analysis has demonstrated that $\beta$-catenin binds specifically to regions within the BACE1 promoter that contain putative T-cell factor/lymphoid enhancer factor (TCF/LEF) motifs, consistent with canonical Wnt target regulation (Parr et al., 2015). Furthermore, TCF4 was found to act as a transcriptional repressor of BACE1. All these results support the concept that the modulation of $\mathrm{Wnt} / \beta$ catenin signaling may be a pathway to potential preventative treatments for AD. 
Studies of Wnt signaling and mitochondria have found that $\beta$-catenin dependent Wnt signaling (via the Wnt3a ligand) prevents the permeabilization of mitochondrial membranes, induced by $\mathrm{A} \beta$ oligomers, through the inhibition of the mitochondrial permeability transition pore. It has also been found that $\beta$-catenin independent Wnt signaling, through the Wnt5a ligand, protects mitochondria from mitochondrial fission-fusion alterations that occur in $A D$, and also modulates B-cell lymphoma 2 (Bcl2) increases, which are induced by A $\beta$ oligomers (Arrázola et al., 2015; Silva-Alvarez et al., 2013). These findings suggest that modulation of Wnt signaling (both $\beta$-catenin dependent and independent) could also protect against ADrelated mitochondrial dysfunction. Another emerging line of evidence links Wnt signaling with the inflammatory response in microglia, which is central to neuroinflammation in neurodegenerative diseases. Disease associated $\beta$-catenin accumulation was shown in microglia in vivo in mice with Alzheimer's-like pathology (Schnurrbusch et al., 1990). The Wnts were also shown to differentially activate $\beta$-catenin dependent and independent signaling in a murine microglia cell line, and are possible regulators of microglia-mediated neuroinflammation (Kilander et al., 2011).

\section{Wnt antagonists as key modulators in AD cell signaling}

Antagonists of Wnt have been shown to work in tandem with Wnt activators during development to promote or inhibit a variety of developmental pathways. They are reported to act either intracellularly by affecting signal transduction, or extracellularly by altering their ability to bind the membrane-receptor complex (Cruciat and Niehrs, 2013). The inhibitors of Wnt are classically grouped into two functional classes: the Dickkopf (Dkk) group of Wnt antagonists comprised of the Dkk family 1-5, which regulate Wnt signaling by binding to the Frizzled co- receptor component LRP5/LRP6; and the secreted frizzled-related protein (sFRP) group, which binds directly either to Wnt or its receptor, FZD, and modulates the 
downstream signals (Kawano and Kypta, 2003). The role of Dkk-1 in response to Wnt signaling, and its antagonistic properties, has been studied extensively by several groups. Higher expression of Dkk-1 has been associated with cell death and DNA damage (Slee et al., 2004), while the expression level of Dkk-1 has been shown to be low in the normal healthy adult brain (Galli et al., 2014; Scott and Brann, 2013). Early reports from studies of cultured cortical neurons describe a potential role of Dkk-1 in the induction of Aß toxicitymediated inhibition of Wnt cascades through interaction with LRP5/6 (Caraci et al., 2008; Caricasole et al., 2004). In parallel, significantly increased expression of Dkk-1 has also been detected in post-mortem AD brains and transgenic mouse AD models (Lieven et al., 2010; Mukhopadhyay et al., 2001); in fact, in one AD mouse model, Dkk-1 has been found to colocalize with hyper-phosphorylated tau-bearing neurons and active GSK3 $\beta$ (Rosi et al., 2010).

Furthermore, in studies of cultured neuronal cells that had high levels of Dkk-1 due to incubation with $\mathrm{A} \beta$ peptides, it was found that antisense knockdown of Dkk-1 resulted in significant inhibition of the A $\beta$-induced hyper-phosphorylation of tau protein (Caricasole et al., 2004). Recent studies of SAMP8 (senescence-accelerated) mice detected higher than normal levels of Dkk-1, activated GSK3 $\beta$, and hyper-phosphorylated tau, along with higher than normal levels of $\beta$-catenin that had been phosphorylated and ready for degradation; and lower protein levels of the anti-apoptotic protein $\mathrm{Bcl} 2$, a Wnt target gene (Itasaki et al., 2003). Together, all these data suggest that Dkk-1 plays a central role in the pathological cascades of $\mathrm{AD}$.

In the $ß$-catenin Wnt pathway, accumulation of $ß$-catenin has been shown to be inhibited by the active binding of Wise/SOST (Sclerostin) antagonist family members through their interaction with either Wnt-1 or Wnt-3a in Xenopus animal cap cells (Bayod et al., 2015). A 
similar observation was reported with other Wnt antagonists such as Wnt inhibitory factor (WIF)-1, which is expressed in the nervous system (Bayod et al., 2015) where it mediates ßcatenin degradation by direct interaction with Wnt ligands. Although there are reports on the Wnt inhibitors acting through the LRP pathway, little is known about the inhibitors acting through the Frizzled receptor, namely the sFRPs, and their role as Wnt inhibitors in neurodegenerative diseases. Here, we review the recent developments in sFRP-Wnt interactions and the emerging role of sFRPs as key Wnt antagonists in AD neuropathology.

\section{sFRPs as multifunctional regulators}

sFRPs are known to bind directly to Wnt, and have sequence and structural similarities with FZD proteins (Rattner et al., 1997; Finch et al., 1997). The sFRP family is comprised of 5 members in which sFRP1, 2, and 5 are clustered together as a group based on their sequence similarities, and are distantly related to the other cluster comprising sFRP3 and sFRP4 (Garcia-Hoyos et al., 2004). Initial studies on sFRPs in Xenopus embryos (Leyns et al., 1997) designated them as Wnt antagonists by their ability to bind to Wnt and block Wnt/ß-catenin signaling. The role of sFRP was further demonstrated in Drosophila (Lin and Perrimon, 1999; Uren et al., 2000) by their ability to inhibit the activity of wingless-ligand Wg, a homologue of Wnt. Since this discovery, the functions of sFRPs have been progressively unravelled to demonstrate that they have multifunctional roles in regulating Wnt signaling in development and disease (Surana et al., 2014). The binding affinity of sFRPs has been shown to vary between their Wnt partners (Galli et al., 2014). and the sFRPs are reported to initiate complex formation with FZD proteins (Kawano and Kypta, 2003; Misra and Matise, 2010), indicating that the molecule could interact not only with Wnt but also with FZD receptors. sFRPs have two independent domains: the N-terminus consisting of a secretory signal peptide and a cysteine-rich domain (CRD), which is identical to the putative Wnt binding site of FZD receptors; and the C-terminus end, which has heparin binding residues and a netrin-related 
motif (NTR) (Dann et al., 2001). The overall functions of the NTR are not defined, yet there are studies reporting its involvement in Wnt binding (Lopez- Rios et al., 2008) and in antagonizing tube formation and promoting apoptosis of human umbilical vein endothelial cells (Longman et al., 2012). Despite the conflicting reports on these two domains in potentiating Wnt activities (Dann et al., 2001; Bovolenta et al., 2008), a parallel study by Bhat et al, has demonstrated the fundamental importance of both domains in modulating Wnt dependent and independent signaling cascades (Bhat et al., 2007). However, due to the sequence resemblance of the CRD with FZD proteins, the CRDs of sFRPs are more recently postulated to be crucial for inhibiting Wnt binding to FZD (Scott and Brann, 2013; MartinManso et al., 2011). The ability of sFRPs to bind FZD via their CRD by forming homo- and heterodimers can also stimulate signal transduction (Carron et al., 2003). The biphasic effect of sFRPs, mainly via their CRD region, is dependent on their concentration and the cellular context. sFRP1 and 2 have been shown to either increase or decrease $\beta$-catenin stabilization depending on the cell type and the expression pattern of the FZD receptors (Xavier et al., 2014). The extracellular stoichiometry of sFRPs, Wnt, and FZD, and the intricate interplay of these molecules with each other is probably a deciding factor in determining whether the balance swings to sFRPs being potentiators or inhibitors of Wnt signaling.

sFRPs can function as signal coordinators when multiple cascades are operating in order to determine cell fate and development. For instance, the role of sFRP1 in regulating neural cell proliferation during development has been demonstrated by Augustine and co-workers (Augustine et al., 2001), where they detected a strong expression of $s F R P-1$ in the developing neocortex of the mouse during the entire period when neurons for the neocortex were being generated and allocated to their final resting positions. sFRP1 has been implicated in 
angiogenesis (Dufourcq et al., 2002), retinal cell differentiation (Kiefer et al., 2013 ) and axon guidance (Drescher, 2005; Rodriguez et al., 2005). A study by Rodriguez et al. [25] reported the possibility of inactivated sFRP1 and 2 being able to perturb retinal neurogenesis in the mouse embryo. A concentration dependent functional role of sFRP1 and 2 in promoting dopaminergic neuron differentiation has also been demonstrated (Kele et al., 2012). Concurrently, a deletion study with sFRP3 alone reported its implication in the neurogenesis of adult hippocampal cells (Jang et al., 2013).

The pro-apoptotic role of sFRP4 has been well established, initially by Dharmarajan and coworkers, in reproductive tissues such as the mammary gland (Constantinou et al., 2008), ovary (Drake et al., 2003), corpus luteum (Guo et al., 1998) and the uterus (Hewitt et al., 2006). However, the apoptotic function of sFRP4 has been rendered inactive in some cancers (He et al., 2005; Brebi et al., 2014). For example, in ovarian cancer, loss of sFRP4 expression results in an aggressive phenotype with poor prognosis (Jacob et al., 2012; Saran et al., 2012). The role of sFRP4 in glioblastoma and head and neck cancers has been recently reported from our group (Warrier et al., 2013; Warrier et al., 2014). We have shown that sFRP4 clearly sensitizes the cancer stem cells to chemotherapeutics by inhibiting the Wnt/ß-catenin pathway and initiating the apoptotic cascade. Additionally, sFRP4 was seen to undergo hypermethylation at the promoter region in several glioma cell lines (Schiefer et al., 2014).Furthermore, we have recently demonstrated the role of sFRP4 in inhibiting the stemness of glioma stem cells and inducing apoptosis (Bhuvanalakshmi et al., 2015). sFRP4 also blocked other typical cancer stem cells traits such as epithelial to mesenchymal transition in glioma stem cells (Bhuvanalakshmi et al., 2015). These studies validate the hypothesis that the downregulation of sFRP4 facilitates cancer stem cell proliferation in brain tumors.

Beyond their role as an inhibitor, sFRPs stabilize Wnts and regulate both Wnt and bone 
morphogenetic protein (BMP) signals for maintaining neural tube functions in vertebrates (Misra and Matise, 2010; Stuckenholz et al., 2013). Furthermore, sFRPs facilitate the diffusion of Wnt ligands extracellularly, thus providing an alternate function to sFRP molecules as Wnt transporters (Mii and Taira, 2009). Altogether, considering these diverse observations on the sFRPs' activity, it can be postulated that they could have a distinct pattern of expression and, depending on the cellular context, sFRPs can either potentiate or regulate several developmental decisions.

\section{Role of sFRP-Wnt interactions in AD development and progression}

Although their detailed mechanism of action and their role in neurodegenerative diseases are poorly understood, sFRP-Wnt interactions could orchestrate a series of sequential events for Alzheimer's progression. Being a member of extracellular Wnt inhibitors, sFRPs function similar to other antagonists, such as Dkk-1 (Inestrosa and Toledo, 2008; Caraci et al., 2008) and WIF -1 (Hu et al., 2008), to modulate the Wnt $\beta$-catenin dependent pathway. Loss or impairment in Wnt signals has been recently marked as a molecular tag in $\mathrm{AD}$ pathogenesis (Inestrosa and Varela-Nallar, 2014). Induction of Dkk-1, and the resultant ß-amyloid toxicity observed in cultured neural cells (Killick et al., 2014; Purro et al., 2014), has been found to be under the mechanistic regulation of a key enzyme modulator of the Wnt pathway, namely GSK3ß. Additionally, GSK3ß has been recently proposed to be the connecting link between the two pathological $\mathrm{AD}$ markers, namely the tau protein containing neurofibrillary tangles (NFT) and the ß-amyloid plaques (Llorens-Martín et al., 2014). Elevated GSK3 $\beta$ activity hasa direct link to increased $A \beta$ production and $A \beta$ deposits, tau hyperphosphorylation, and synaptic damage in AD patients (Reddy et al., 2000; Benedetti et al., 2013). Although evidence on the direct interactions of sFRPs on regulating Wnt activity in the AD brain is lacking, their functional role in attenuating ß-catenin signaling has been demonstrated to be via GSK3ß (Bovolento et al., 2010). Moreover, sFRPs are reported to be involved in the 
decline of both cytoplasmic and membrane associated ß-catenin in other cellular contexts that include pancreatic islets (Lee et al., 2008), retinal cells (Esteve et al., 2003), and caudal neural tubes (Dann et al., 2001). Conversely, an sFRP1 deletion study in mice demonstrated reinstated Wnt pathway activation and signaling (Gong et al., 2014), suggesting the potential involvement of these proteins in Wnt related functions. Unlike Dkks, sFRPs can interact with both ß-catenin dependent and independent Wnt signaling pathways (Marchetti and Pluchino, 2013; Muley et al., 2010). Therefore, in an sFRP over-expressed system, they antagonize Wnt actions either by binding directly to Wnts or competing with FZD receptors, and thus preventing Wnt-FZD interactions. As a result of these interactions, the GSK3ß enzyme in the destruction complex targets $ß$-catenin to ubiquitin-mediated degradation cycles. One can speculate that this inhibition of Wnt/ß-catenin-mediated signaling could result in the accumulation of tau protein and the formation of NFT in the AD brain. This, in turn, disrupts nuclear localization of $ß$-catenin and activation of the TCF/LEF promoter, which initiates apoptosis that could lead to neuronal instability and formation of amyloid plaques (Fig.2). Subsequent depletion of ß-catenin levels has been correlated to the presence of amyloid plaques during the progressive phases of $\mathrm{AD}$ (Maguschak and Ressler, 2012). Thus, the previously observed inverse relation between ß-catenin signaling and GSK3ß activity in AD brains (Avrahami et al., 2013; Hernández et al., 2010) and rat hippocampal neurons (SalcedoTello et al., 2011) leads us to speculate that there is another possible involvement of sFRPs as mediators in deregulating the Wnt signaling pathway. Another study demonstrated that Wnt5a was able to reduce synaptic damage and protect against memory loss in $\mathrm{AD}$, and that this beneficial effect was blocked by sFRP2 (Zhang et al., 2015). Although further substantiation of their functions in neuro-regulatory activities is required, one can expect to recapitulate sFRP-mediated events in the AD brain similar to the reported functions of Dkk-1 (LlorensMartín et al., 2014), but with wider implications because of the involvement of multiple 
cascades of the Wnt pathway in sFRP signal transduction. Hence, it would be worthwhile to consider sFRPs in a wider aspect to understand their mechanistic role as Wnt inhibitors in neuroderegulation.

\section{sFRPs as potential therapeutic targets for $\mathrm{AD}$ treatment}

In comparison to Dkk-1 or other Wnt inhibitors, sFRP-based targeted strategies are in the early stages of investigation (Fontenot et al., 2013). Expression profiling studies of sFRPs have demonstrated their up-regulation in most neurological diseases (Esteve et al., 2011; Stuckenholz et al., 2013). However, no study has explicitly identified the neuro-regulatory activities of sFRPs in Alzheimer's progression. Given the complexity of the action of sFRPs on Wnt signaling, it is possible this family of Wnt mediators could have a diverse effect on $\mathrm{AD}$ progression. Depending on their expression levels and cellular context within the CNS, sFRPs could simultaneously interact with Wnt and FZD to elicit varied responses. A systematic delineation of expression the sFRP family of proteins in AD progression would help to determine sFRPs as stage-specific biomarkers and as therapeutic targets in the degenerative neuropathology of $\mathrm{AD}$. As sFRPs have a broad effect across the multiple pathways of Wnt signaling, such an approach would help in a wider capture of the neurodegeneration caused by a dysfunctional Wnt machinery. A deeper understanding of the molecular mechanism of action of sFRPs in Wnt regulation, in the context of Alzheimer's neurodegeneration, could provide a framework for designing novel sFRP-targeted therapies in $\mathrm{AD}$.

The effect of sFRP on Wnt signaling in the CNS is most likely to be inhibitory because of its binding to both the ligand and the receptor. The binding to FZD by the CRD domain of sFRP may not be sufficient to elicit the complex assembly of the Axin conglomerate, required for the downstream activation of $ß$-catenin. The binding at the FZD receptor could be further 
exacerbated by $A ß$ also binding to FZD close to the binding site of Wnt. Targeting the sFRPs to relieve its suppression on the Wnt pathway could be achieved by designing small molecule inhibitors for different sFRPs, similar to the diarylsulfone sulphonamide inhibitor for sFRP1 (Bodine et al., 2009), obtained by high throughput screening.

\section{Conclusion}

The need to identify dysfunctional regulatory networks in $\mathrm{AD}$ is compelling in order to design novel and effective drug targets. As the present modalities in $\mathrm{AD}$ therapies are mostly aimed at administering symptomatic treatments, there is a direct need for causative targeting of the disease, which will not only help in $\mathrm{AD}$ regression but also in early pre-symptomatic identification of the disease. With the advent of early biomarkers for $\mathrm{AD}$ related to the Wnt pathway, there could be hope for more accurate and early diagnosis and promising therapy for this debilitating disease. Therefore, we propose that sFRPs could have a profound role in $\mathrm{AD}$ and could be exploited as novel biomarkers for early detection. Targeting sFRPs might be a more promising strategy than other inhibitors such as GSK3ß or DKK because of the ability of sFRPs to modulate the multiple Wnt-driven signaling events. Furthermore, as a corollary, targeting their expression could bring about amelioration of neurodegenerative changes associated with AD.

\section{Conflict of Interest}

The authors declare no conflict of interest.

\section{Acknowledgments}

SW thanks the Department of Biotechnology, India for partial funding (BT/PR8493/MED/31/226/2013). GB acknowledges Manipal University for fellowship under the structured $\mathrm{PhD}$ program. 


\section{References}

Aisen PS. Inflammation and Alzheimer's disease: mechanisms and therapeutic strategies. Gerontology. 1997; 43(1-2):143-9.

Alonso L, Fuchs E. Stem cells in the skin: waste not, Wnt not. Genes Dev. 2003; 17(10): 1189-200.

Arenas E. Wnt signaling in midbrain dopaminergic neuron development and regenerative medicine for Parkinson's disease. J Mol Cell Biol. 2014; 6(1):42-53.

Armstrong RA. The pathogenesis of Alzheimer's disease: a reevaluation of the "amyloid cascade hypothesis".Int J Alzheimers Dis. 2011; 2011:630865.

Arrázola MS, Silva-Alvarez C, Inestrosa NC. How the Wnt signaling pathway protects from neurodegeneration: the mitochondrial scenario. Front Cell Neurosci. 2015; 9:166.

Augustine C, Gunnersen J, Spirkoska V, Tan SS. Place- and time-dependent expression of mouse sFRP-1 during development of the cerebral neocortex. Mech Dev. 2001; 109(2): 395-7.

Avrahami L, Farfara D, Shaham-Kol M, Vassar R, Frenkel D, Eldar-Finkelman H. Inhibition of glycogen synthase kinase-3 ameliorates $\beta$-amyloid pathology and restores lysosomal acidification and mammalian target of rapamycin activity in the Alzheimer disease mouse model: in vivo and in vitro studies. J Biol Chem. 2013; 288(2): 1295-306.

Bayod S, Felice P, Andrés P, Rosa P, Camins A, Pallàs M, Canudas AM. Downregulation of canonical Wnt signaling in hippocampus of SAMP8 mice. Neurobiol Aging. 2015; 36(2): 720-9.

Benedetti F, Bollettini I, Barberi I, Radaelli D, Poletti S, Locatelli C, Pirovano A, Lorenzi C, Falini A, Colombo C, Smeraldi E. Lithium and GSK3- $\beta$ promoter gene variants influence white matter microstructure in bipolar disorder. Neuropsychopharmacology. 2013 ; 38(2): 313-27.

Bhat R, Xue Y, Berg S, Hellberg S, Ormö M, Nilsson Y, Radesäter AC, Jerning E, Markgren PO, Borgegård T, Nylöf M, Giménez-Cassina A, Hernández F, Lucas JJ, Díaz-Nido J, Avila J. Structural insights and biological effects of glycogen synthase kinase 3-specific inhibitor AR-A014418. J Biol Chem. 2003; 278(46): 45937-45.

Bhat RA, Stauffer B, Komm BS, Bodine PV. Structure-function analysis of secreted frizzled-related protein-1 for its Wnt antagonist function. J Cell Biochem. 2007; 102(6): 1519-28.

Bhuvanalakshmi G, Arfuso F, Millward M, Dharmarajan A, Warrier S. Secreted frizzledrelated protein 4 inhibits glioma stem-like cells by reversing epithelial to mesenchymal transition, inducing apoptosis and decreasing cancer stem cell properties. PLoS One. 2015; 10(6): e0127517.

Blennow K, de Leon MJ, Zetterberg H. Alzheimer's disease. Lancet. 2006; 368(9533): 387-403. 
Bodine PV, Stauffer B, Ponce-de-Leon H, Bhat RA, Mangine A, Seestaller-Wehr LM, Moran RA, Billiard J, Fukayama S, Komm BS, Pitts K, Krishnamurthy G,Gopalsamy A, Shi M, Kern JC, Commons TJ, Woodworth RP, Wilson MA, Welmaker GS, Trybulski EJ, Moore WJ. A small molecule inhibitor of the Wnt antagonist secreted frizzled-related protein-1 stimulates bone formation. Bone. 2009; 44(6): 1063-8.

Bovolenta P, Esteve P, Ruiz JM, Cisneros E, Lopez-Rios J. Beyond Wnt inhibition: new functions of secreted Frizzled-related proteins in development and disease. J Cell Sci. 2008; 121(Pt 6): 737-46.

Brebi P, Hoffstetter R, Andana A, Ili CG, Saavedra K, Viscarra T, Retamal J, Sanchez R, Roa JC. Evaluation of ZAR1 and SFRP4 methylation status as potentials biomarkers for diagnosis in cervical cancer: exploratory study phase I. Biomarkers. 2014; 19(3):1818.

Brown GC, Bal-Price A. Inflammatory neurodegeneration mediated by nitric oxide, glutamate, and mitochondria. Mol Neurobiol. 2003; 27(3):325-55.

Caraci F, Busceti C, Biagioni F, Aronica E, Mastroiacovo F, Cappuccio I, Battaglia G, Bruno V, Caricasole A, Copani A, Nicoletti F. The Wnt antagonist, Dickkopf-1, as a target for the treatment of neurodegenerative disorders. Neurochem Res. 2008; 33(12): 2401-6.

Caricasole A, Copani A, Caraci F, Aronica E, Rozemuller AJ, Caruso A, Storto M, Gaviraghi G, Terstappen GC, Nicoletti F. Induction of Dickkopf-1, a negative modulator of the Wnt pathway, is associated with neuronal degeneration in Alzheimer's brain. J Neurosci. 2004; 24(26): 6021-7.

Carron C, Pascal A, Djiane A, Boucaut JC, Shi DL, Umbhauer M. Frizzled receptor dimerization is sufficient to activate the Wnt/beta-catenin pathway. Cell Sci. 2003; 116(Pt 12): 2541-50.

Chen Y, Bodles AM. Amyloid precursor protein modulates beta-catenin degradation. J Neuroinflammation. 2007; 4:29.

Coghlan MP, Culbert AA, Cross DA, Corcoran SL, Yates JW, Pearce NJ, Rausch OL, Murphy GJ, Carter PS, Roxbee Cox L, Mills D, Brown MJ, Haigh D, Ward RW, Smith DG, Murray KJ, Reith AD, Holder JC. Selective small molecule inhibitors of glycogen synthase kinase-3 modulate glycogen metabolism and gene transcription. Chem Biol. 2000; 7(10): 793-803.

Constantinou T, Baumann F, Lacher MD, Saurer S, Friis R, Dharmarajan A. SFRP-4 abrogates Wnt-3a-induced beta-catenin and Akt/PKB signalling and reverses a Wnt-3aimposed inhibition of in vitro mammary differentiation. J Mol Signal. 2008; 3:10.

Cruciat CM, Niehrs C. Secreted and transmembrane wnt inhibitors and activators. Cold Spring Harb Perspect Biol. 2013; 5(3): a015081.

Dann CE, Hsieh JC, Rattner A, Sharma D, Nathans J, Leahy DJ. Insights into Wnt binding and signalling from the structures of two Frizzled cysteine-rich domains. Nature. 2001; 412(6842): 86-90. 
Drake JM, Friis RR, Dharmarajan AM. The role of sFRP4, a secreted frizzled-related protein, in ovulation. Apoptosis. 2003; 8(4): 389-97.

Drescher U. A no-Wnt situation: SFRPs as axon guidance molecules. Nat Neurosci. 2005;8(10): 1281-2.

Dufourcq P, Couffinhal T, Ezan J, Barandon L, Moreau C, Daret D, Duplàa C. FrzA, a secreted frizzled related protein, induced angiogenic response. Circulation. 2002; 106(24):3097-103.

Esteve P, Sandonìs A, Ibañez C, Shimono A, Guerrero I, Bovolenta P. Secreted frizzledrelated proteins are required for $\mathrm{Wnt} / \beta$-catenin signalling activation in the vertebrate optic cup. Development. 2011; 138(19): 4179-84.

Esteve P, Trousse F, Rodríguez J, Bovolenta P. SFRP1 modulates retina cell differentiation through a beta-catenin-independent mechanism. J Cell Sci. 2003; 116(Pt 12): 2471-81.

Finch PW, He X, Kelley MJ, Uren A, Schaudies RP, Popescu NC, Rudikoff S, Aaronson SA, Varmus HE, Rubin JS. Purification and molecular cloning of a secreted, Frizzledrelated antagonist of Wnt action. Proc Natl Acad Sci U S A. 1997; 94(13): 6770-5.

Fontenot E, Rossi E, Mumper R, Snyder S, Siamakpour RS, Ma P, Hilliard E, Bone B, Ketelsen D, Santos C, Patterson C, Klauber DN. A novel monoclonal antibody to secreted frizzled-related protein 2 inhibits tumor growth. Mol Cancer Ther. 2013 ; 12(5): 685-95.

Fuentealba RA, Farias G, Scheu J, Bronfman M, Marzolo MP, Inestrosa NC. Signal transduction during amyloid-beta-peptide neurotoxicity: role in Alzheimer disease. Brain Res Brain Res Rev. 2004; 47(1-3): 275-89.

Galli LM, Barnes T, Cheng T, Acosta L, Anglade A, Willert K, Nusse R, Burrus LW. Differential inhibition of Wnt-3a by Sfrp-1, Sfrp-2, and Sfrp-3. Dev Dyn. 2006; 235(3): 681-90.

Galli S, Lopes DM, Ammari R, Kopra J, Millar SE, Gibb A, Salinas PC. Deficient Wnt signalling triggers striatal synaptic degeneration and impaired motor behaviour in adult mice. Nat Commun. 2014; 5:4992.

Garcia-Hoyos M, Cantalapiedra D, Arroyo C, Esteve P, Rodríguez J, Riveiro R, Trujillo MJ, Ramos C, Bovolenta P, Ayuso C. Evaluation of SFRP1 as a candidate for human retinal dystrophies. Mol Vis. 2004; 10:426-31.

Ghosal K, Vogt DL, Liang M, Shen Y, Lamb BT, Pimplikar SW. Alzheimer's diseaselike pathological features in transgenic mice expressing the APP intracellular domain. Proc Natl Acad Sci U S A. 2009 Oct 27; 106(43): 18367-72.

Godoy JA, Rios JA, Zolezzi JM, Braidy N, Inestrosa NC. Signaling pathway cross talk in Alzheimer's disease. Cell Commun Signal. 2014; 12:23.

Gong Y, Xu CY, Wang JR, Hu XH, Hong D, Ji X, Shi W, Chen HX, Wang HB, Wu XM. Inhibition of phosphodiesterase 5 reduces bone mass by suppression of canonical Wnt signaling. Cell Death Dis. 2014; 5:e1544. 
Gouras GK, Tampellini D, Takahashi RH, Capetillo-Zarate E. Intraneuronal beta-amyloid accumulation and synapse pathology in Alzheimer's disease. Acta Neuropathol. 2010; 119(5):523-41.

Grimm MO, Mett J, Stahlmann CP, Grösgen S, Haupenthal VJ, Blümel T, Hundsdörfer B, Zimmer VC, Mylonas NT, Tanila H, Müller U, Grimm HS,Hartmann T. APP intracellular domain derived from amyloidogenic $\beta$ - and $\gamma$-secretase cleavage regulates neprilysin expression. Front Aging Neurosci. 2015 ; 7:77.

Guo K, Wolf V, Dharmarajan AM, Feng Z, Bielke W, Saurer S, Friis R. Apoptosisassociated gene expression in the corpus luteum of the rat. Biol Reprod. 1998; 58(3): 73946.

Harrison-Uy SJ, Pleasure SJ. Wnt signaling and forebrain development. Cold Spring Harb Perspect Biol. 2012; 4(7): a008094.

He B, Lee AY, Dadfarmay S, You L, Xu Z, Reguart $\quad$ N, Mazieres J, Mikami I, McCormick F, Jablons DM. Secreted frizzled-related protein 4 is silenced by hypermethylation and induces apoptosis in beta-catenin-deficient human mesothelioma cells. Cancer Res. 2005; 65(3):743-8.

Hernández F, Gómez de Barreda E, Fuster-Matanzo A, Lucas JJ, Avila J. GSK3: a possible link between beta amyloid peptide and tau protein. Exp Neurol. 2010; 223(2): 322-5.

Hewitt DP, Mark PJ, Dharmarajan AM, Waddell BJ. Placental expression of secreted frizzled related protein- 4 in the rat and the impact of glucocorticoid-induced fetal and placental growth restriction. Biol Reprod. 2006; 75(1): 75-81.

Hu YA, Gu X, Liu J, Yang Y, Yan Y, Zhao C. Expression pattern of Wnt inhibitor factor 1(Wif1) during the development in mouse CNS. Gene Expr Patterns. 2008;8(7-8): 51522.

Inestrosa NC, Arenas E. Emerging roles of Wnts in the adult nervous system. Nat Rev Neurosci. 2010; 11(2):77-86.

Inestrosa NC, Toledo EM. The role of Wnt signaling in neuronal dysfunction in Alzheimer's disease. Mol Neurodegener. 2008 ; 3:9.

Inestrosa NC, Varela-Nallar L. Wnt signaling in the nervous system and in Alzheimer's disease. J Mol Cell Biol. 2014; 6(1): 64-74.

Itasaki N, Jones CM, Mercurio S, Rowe A, Domingos PM, Smith JC, Krumlauf R. Wise, a context-dependent activator and inhibitor of Wnt signalling. Development. 2003; 130(18): 4295-305.

Ittner LM, Götz J. Amyloid- $\beta$ and tau--a toxic pas de deux in Alzheimer's disease. Nat Rev Neurosci. 2011; 12(2): 65-72.

Jacob F, Ukegjini K, Nixdorf S, Ford CE, Olivier J, Caduff R, Scurry JP, Guertler R, Hornung D, Mueller R, Fink DA, Hacker NF, Heinzelmann-Schwarz VA. Loss of secreted frizzled-related protein 4 correlates with an aggressive phenotype and predicts poor outcome in ovarian cancer patients. PLoS One. 2012; 7(2): e31885. 
Jucker M, Walker LC. Self-propagation of pathogenic protein aggregates in neurodegenerative diseases. Nature. 2013; 501(7465): 45-51.

Kahn M. Can we safely target the WNT pathway? Nat Rev Drug Discov. 2014; 13(7): 513-32.

Kaidanovich-Beilin O, Milman A, Weizman A, Pick CG, Eldar-Finkelman $H$. Rapid antidepressive-like activity of specific glycogen synthase kinase-3 inhibitor and its effect on beta-cateninin mouse hippocampus. Biol Psychiatry. 2004 ; 55(8): 781-4.

Kawano Y, Kypta R. Secreted antagonists of the Wnt signalling pathway. J Cell Sci. 2003; 116(Pt 13): 2627-34.

Kele J, Andersson ER, Villaescusa JC, Cajanek L, Parish CL, Bonilla S, Toledo EM, Bryja V, Rubin JS, Shimono A, Arenas E. SFRP1 and SFRP2 dose-dependently regulate midbrain dopamine neuron development in vivo and in embryonic stem cells. Stem Cells. 2012; 30(5): 865-75.

Kiefer AK, Tung JY, Do CB, Hinds DA, Mountain JL, Francke U, Eriksson N.Genomewide analysis points to roles for extracellular matrix remodeling, the visual cycle, and neuronal development in myopia. PLoS Genet. 2013; 9(2): e1003299.

Kilander MB, Halleskog C, Schulte G. Recombinant WNTs differentially activate $\beta$ catenin-dependent and -independent signalling in mouse microglia-like cells. Acta Physiol (Oxf). 2011; 203(3): 363-72.

Killick R, Ribe EM, Al-Shawi R, Malik B, Hooper C, Fernandes C, Dobson R, Nolan PM, Lourdusamy A, Furney S, Lin K, Breen G, Wroe R, To AW,Leroy K, Causevic M, Usardi A, Robinson M, Noble W, Williamson R, Lunnon K, Kellie S, Reynolds $\mathrm{CH}$, Bazenet C, Hodges A, Brion JP, Stephenson J, Simons JP, Lovestone S. Clusterin regulates $\beta$-amyloid toxicity via Dickkopf-1-driven induction of the wnt-PCP-JNK pathway. Mol Psychiatry. 2014; 19(1): 88-98.

King MK, Pardo M, Cheng Y, Downey K, Jope RS, Beurel E. Glycogen synthase kinase3 inhibitors: Rescuers of cognitive impairments. Pharmacol Ther. 2014; 141(1): 1-12.

Leclerc S, Garnier M, Hoessel R, Marko D, Bibb JA, Snyder GL, Greengard P, Biernat J, Wu YZ, Mandelkow EM, Eisenbrand G, Meijer L. Indirubins inhibit glycogen synthase kinase-3 beta and CDK5/p25, two protein kinases involved in abnormal tau phosphorylation in Alzheimer's disease. A property common to most cyclin-dependent kinase inhibitors? J Biol Chem. 2001; 276(1): 251-60.

Lee SH, Demeterco C, Geron I, Abrahamsson A, Levine F, Itkin-Ansari P. Islet specific Wnt activation in human type II diabetes. Exp Diabetes Res. 2008; 2008:728763.

Leost M, Schultz C, Link A, Wu YZ, Biernat J, Mandelkow EM, Bibb JA, Snyder GL, Greengard P, Zaharevitz DW, Gussio R, Senderowicz AM, Sausville EA,Kunick C, Meijer L. Paullones are potent inhibitors of glycogen synthase kinase-3beta and cyclindependent kinase 5/p25. Eur J Biochem. 2000; 267(19): 5983-94.

Leyns L, Bouwmeester T, Kim SH, Piccolo S, De Robertis EM. Frzb-1 is a secreted antagonist of Wnt signaling expressed in the Spemann organizer. Cell. 1997; 88(6): 74756. 
Lieven O, Knobloch J, Rüther U. The regulation of Dkk1 expression during embryonic development. Dev Biol. 2010; 340(2): 256-68.

Lin X, Perrimon N. Dally cooperates with Drosophila Frizzled 2 to transduce Wingless signalling. Nature. 1999; 400(6741): 281-4.

Lindberg C, Hjorth E, Post C, Winblad B, Schultzberg M. Cytokine production by a human microglial cell line: effects of beta-amyloid and alpha-melanocyte-stimulating hormone. Neurotox Res. 2005;8(3-4): 267-76.

Liu CC, Tsai CW, Deak F, Rogers J, Penuliar M, Sung YM, Maher JN, Fu Y, Li X, Xu H, Estus S, Hoe HS, Fryer JD, Kanekiyo T, Bu G. Deficiency in LRP6-mediated Wnt signaling contributes to synaptic abnormalities and amyloid pathology in Alzheimer's disease. Neuron. 2014; 84(1): 63-77.

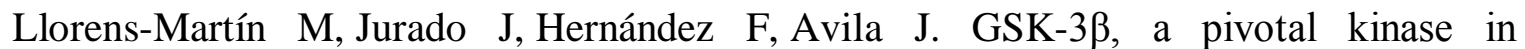
Alzheimer disease. Front Mol Neurosci. 2014; 7:46.

Longman D, Arfuso F, Viola HM, Hool LC, Dharmarajan AM. The role of the cysteinerich domain and netrin-like domain of secreted frizzled-related protein 4 in angiogenesis inhibition in vitro. Oncol Res. 2012; 20(1): 1-6.

Lopez-Rios J, Esteve P, Ruiz JM, Bovolenta P. The Netrin-related domain of Sfrp1 interacts with Wnt ligands and antagonizes their activity in the anterior neural plate. Neural Dev. 2008; 3:19.

MacDonald BT, He X. Frizzled and LRP5/6 receptors for Wnt/ $\beta$-catenin signaling. Cold Spring Harb Perspect Biol. 2012; 4(12).

Magdesian MH, Carvalho MM, Mendes FA, Saraiva LM, Juliano MA, Juliano L, GarciaAbreu J, Ferreira ST. Amyloid-beta binds to the extracellular cysteine-rich domain of Frizzled and inhibits Wnt/beta-catenin signaling. J Biol Chem. 2008; 283(14): 9359-68.

Maguschak KA, Ressler KJ. A role for $\mathrm{WNT} / \beta$-catenin signaling in the neural mechanisms of behavior. J Neuroimmune Pharmacol. 2012 ; 7(4): 763-73.

Malhotra S, Kincade PW. Wnt-related molecules and signaling pathway equilibrium in hematopoiesis. Cell Stem Cell. 2009; 4(1): 27-36.

Marchetti B, Pluchino S. Wnt your brain be inflamed? Yes, it Wnt! Trends Mol Med. 2013; 19(3): 144-56.

Martin BL, Kimelman D. Canonical Wnt signaling dynamically controls multiple stem cell fate decisions during vertebrate body Dev Cell. 2012; 22(1):223-32.

Martin-Manso G, Calzada MJ, Chuman Y, Sipes JM, Xavier CP, Wolf V, Kuznetsova SA, Rubin JS, Roberts DD. sFRP-1 binds via its netrin-related motif to the N-module of thrombospondin-1 and blocks thrombospondin-1 stimulation of MDA-MB-231 breast carcinoma cell adhesion and migration. Arch Biochem Biophys. 2011; 509(2): 147-56.

Martinez A, Perez DI. GSK-3 inhibitors: a ray of hope for the treatment of Alzheimer's disease? J Alzheimers Dis. 2008; 15(2): 181-91. 
Melo A, Monteiro L, Lima RM, Oliveira DM, Cerqueira MD, El-Bachá RS. Oxidative stress in neurodegenerative diseases: mechanisms and therapeutic perspectives. Oxid Med Cell Longev. 2011; 2011:467180.

Mii Y, Taira M. Secreted Frizzled-related proteins enhance the diffusion of Wnt ligands and expand their signalling range. Development. 2009; 136(24): 4083-8.

Misra K, Matise MP. A critical role for sFRP proteins in maintaining caudal neural tube closure in mice via inhibition of BMP signaling. Dev Biol. 2010; 337(1): 74-83.

Mukhopadhyay M, Shtrom S, Rodriguez-Esteban C, Chen L, Tsukui T, Gomer L, Dorward DW, Glinka A, Grinberg A, Huang SP, Niehrs C, Izpisúa Belmonte JC,Westphal H. Dickkopf1 is required for embryonic head induction and limb morphogenesis in the mouse. Dev Cell. 2001; 1(3): 423-34.

Muley A, Majumder S, Kolluru GK, Parkinson S, Viola H, Hool L, Arfuso F, Ganss R, Dharmarajan A, Chatterjee S. Secreted frizzled-related protein 4: an angiogenesis inhibitor. Am J Pathol. 2010; 176(3): 1505-16.

Murase S, Mosser E, Schuman EM. Depolarization drives beta-Catenin into neuronal spines promoting changes in synaptic structure and function. Neuron. 2002; 35(1): 91105.

Palomo V, Soteras I, Perez DI, Perez C, Gil C, Campillo NE, Martinez A. Exploring the binding sites of glycogen synthase kinase 3. Identification and characterization of allosteric modulation cavities. J Med Chem. 2011; 54(24): 8461-70.

Parr C, Mirzaei N, Christian M, Sastre M. Activation of the Wnt/ $\beta$-catenin pathway represses the transcription of the $\beta$-amyloid precursor protein-cleaving enzyme (BACE1) via binding of T-cell factor-4 to BACE1 promoter. FASEB J. 2015; 29(2): 623-35.

Paul S, Dey A. Wnt signaling and cancer development: therapeutic implication. Neoplasma. 2008; 55(3): 165-76.

Phiel CJ, Wilson CA, Lee VM, Klein PS. GSK-3alpha regulates production of Alzheimer's disease amyloid-beta peptides. Nature. 2003; 423(6938): 435-9.

Plotkin B, Kaidanovich O, Talior I, Eldar-Finkelman H. Insulin mimetic action of synthetic phosphorylated peptide inhibitors of glycogen synthase kinase-3. J Pharmacol Exp Ther. 2003; 305(3):974-80.

Purro SA, Galli S, Salinas PC. Dysfunction of Wnt signaling and synaptic disassembly in neurodegenerative diseases. J Mol Cell Biol. 2014; 6(1): 75-80.

Quinlan R, Graf M, Mason I, Lumsden A, Kiecker C. Complex and dynamic patterns of Wnt pathway gene expression in the developing chick forebrain. Neural Dev. 2009; 4:35.

Rattner A, Hsieh JC, Smallwood PM, Gilbert DJ, Copeland NG, Jenkins NA, Nathans J. A family of secreted proteins contains homology to the cysteine-rich ligand-binding domain of frizzled receptors. Proc Natl Acad Sci U S A. 1997; 94(7): 2859-63.

Reddy MP, Kinney CA, Chaikin MA, Payne A, Fishman-Lobell J, Tsui P, Dal Monte PR, Doyle ML, Brigham-Burke MR, Anderson D, Reff M, Newman R, Hanna N, Sweet 
RW, Truneh A. Elimination of Fc receptor-dependent effector functions of a modified IgG4 monoclonal antibody to human CD4. J Immunol. 2000; 164(4): 1925-33.

Rodriguez J, Esteve P, Weinl C, Ruiz JM, Fermin Y, Trousse F, Dwivedy A, Holt C, Bovolenta P. SFRP1 regulates the growth of retinal ganglion cell axons through the Fz2 receptor. Nat Neurosci. 2005;8(10): 1301-9.

Rosi MC, Luccarini I, Grossi C, Fiorentini A, Spillantini MG, Prisco A, Scali C, Gianfriddo M, Caricasole A, Terstappen GC, Casamenti F. Increased Dickkopf-1 expression in transgenic mouse models of neurodegenerative disease. J Neurochem. 2010; 112(6): 1539-51.

Ross CA, Poirier MA. Protein aggregation and neurodegenerative disease. Nat Med. 2004; 10 Suppl: S10-7.

Ryan KA, Pimplikar SW. Activation of GSK-3 and phosphorylation of CRMP2 in transgenic mice expressing APP intracellular domain. J Cell Biol. 2005; 171(2): 327-35.

Salcedo-Tello P, Ortiz-Matamoros A, Arias C. GSK3 Function in the Brain during Development, Neuronal Plasticity, and Neurodegeneration. Int J Alzheimers Dis. 2011; 2011:189728.

Sanchez S, Sayas CL, Lim F, Diaz-Nido J, Avila J, Wandosell F. The inhibition of phosphatidylinositol-3-kinase induces neurite retraction and activates GSK3. J Neurochem. 2001 ; 78(3): 468-81.

Saran U, Arfuso F, Zeps N, Dharmarajan A. Secreted frizzled-related protein 4 expression is positively associated with responsiveness to cisplatin of ovarian cancer cell lines in vitro and with lower tumour grade in mucinous ovarian cancers. BMC Cell Biol. 2012; 13:25.

Schiefer L, Visweswaran M, Perumal V, Arfuso F, Groth D, Newsholme P, Warrier $\mathrm{S}$, Dharmarajan A. Epigenetic regulation of the secreted frizzled-related protein family in human glioblastoma multiforme. Cancer Gene Ther. 2014; 21(7): 297-303.

Schnurrbusch U, Ullrich E, Elze K. Histologic and biochemical studies on the uteri of ovariectomized gilts duringthe first two months of pregnancy

after different hormone substitutions.1. Changes in the structure of the placenta during pregnancy week's 38after constant high doses of progesterone and est radiolbenzoate. Arch Exp Veterinarmed. 1990; 44(5): 671-84.

Scott EL, Brann DW. Estrogen regulation of Dkk1 and Wnt/ $\beta$-Catenin signaling in neurodegenerative disease. Brain Res. 2013; 1514:63-74.

Silva-Alvarez C, Arrázola MS, Godoy JA, Ordenes D, Inestrosa NC. Canonical Wnt signaling protects hippocampal neurons from $A \beta$ oligomers: role of non-canonical Wnt$5 \mathrm{a} / \mathrm{Ca}(2+)$ in mitochondrial dynamics. Front Cell Neurosci. 2013 ; 7:97.

Slee EA, O'Connor DJ, Lu X. To die or not to die: how does p53 decide? Oncogene. 2004; 23(16): 2809-18.

Stuckenholz C, Lu L, Thakur PC, Choi TY, Shin $\quad$ D, Bahary N. Sfrp5 modulates both Wnt and BMP signaling and regulates gastrointestinal organogenesi s [corrected] in thezebrafish, Danio rerio. PLoS One. 2013;8(4): e62470. 
Surana R, Sikka S, Cai W, Shin EM, Warrier SR, Tan HJ, Arfuso F, Fox SA, Dharmarajan AM, Kumar AP. Secreted frizzled related proteins: Implications in cancers. Biochim Biophys Acta. 2014; 1845(1): 53-65.

Uren A, Reichsman F, Anest V, Taylor WG, Muraiso K, Bottaro DP, Cumberledge $\mathrm{S}$, Rubin JS. Secreted frizzled-related protein-1 binds directly to Wingless and is a biphasic modulator of Wnt signaling. J Biol Chem. 2000; 275(6): 4374-82.

Valvezan AJ, Klein PS. GSK-3 and Wnt Signaling in Neurogenesis and Bipolar Disorder. Front Mol Neurosci. 2012 ; 5:1.

van Amerongen R, Nusse R. Towards an integrated view of Wnt signaling in development. Development. 2009; 136(19): 3205-14.

Varela-Nallar L, Inestrosa NC. Wnt signaling in the regulation of adult hippocampal neurogenesis. Front Cell Neurosci. 2013; 7:100.

Wan W, Xia S, Kalionis B, Liu L, Li Y. The role of Wnt signaling in the development of Alzheimer's disease: a potential therapeutic target? Biomed Res Int. 2014; 2014:301575.

Warrier S, Balu SK, Kumar AP, Millward M, Dharmarajan A. Wnt antagonist, secreted frizzled-related protein 4 (sFRP4), increases chemotherapeutic response of glioma stemlike cells. Oncol Res. 2013; 21(2): 93-102.

Warrier S, Bhuvanalakshmi G, Arfuso F, Rajan G, Millward M, Dharmarajan A. Cancer stem-like cells from head and neck cancers are chemosensitized by the Wnt antagonist, sFRP4, by inducing apoptosis, decreasing stemness, drug resistance and epithelial to mesenchymal transition. Cancer Gene Ther. 2014; 21(9): 381-8.

Willert K, Nusse R. Wnt proteins. Cold Spring Harb Perspect Biol. 2012; 4(9): a007864.

Xavier CP, Melikova M, Chuman Y, Üren A, Baljinnyam B, Rubin JS. Secreted Frizzledrelated protein potentiation versus inhibition of Wnt3a/ $\beta$-catenin signaling. Cell Signal. 2014; 26(1): 94-101.

Zhang GL, Zhang J, Li SF, Lei L, Xie HY, Deng F, Feng JC, Qi JS. Wnt-5a prevents A $\beta$ induced deficits in long-term potentiation and spatial memory in rats. Physiol Behav. 2015; 149:95-100.

Zhou F, Gong K, van Laar T, Gong Y, Zhang L. Wnt/ $\beta$-catenin signal pathway stabilizes APP intracellular domain (AICD) and promotes its transcriptional activity. Biochem Biophys Res Commun. 2011 ; 412(1): 68-73.

\section{FIGURE LEGENDS}

\section{Fig 1. The $\beta$-catenin dependent and independent pathways of Wnt signaling}

Extracellular ligand Wnt acts through the $\beta$-catenin dependent or via the $\beta$-catenin independent pathways, through the Frizzled (FZD) receptor and via the activation of intracellular disheveled (DVL) or heteromeric G-proteins. In the $\beta$-catenin dependent pathway, $\beta$-catenin is activated and transported to the nucleus for downstream activation 
of Wnt target genes via the T-cell factor/Lymphoid enhancer factor (TCF/LEF) promotor. In the $\beta$-catenin independent pathway, binding of Wnt to FZD activates either the $\mathrm{Ca}^{2+}$ pathway or the planar cell polarity pathway, which are involved in cell survival and cytoskeletal formation through actin regulation. (CAMK-Calcium/calmodulindependent protein kinase, protein kinase C - PKC, Jun-N-terminal kinase- JNK, Activating transcription factor 2- ATF-2, cAMP-response element-binding proteinCREB, N-Methyl-D-aspartate receptors- NMDAR, post synaptic density-95- PSD-95).

Fig 2. A model for sFRP-mediated inhibition of the Wnt signaling pathways in Alzheimer's disease

In the Alzheimer's brain, over-expressed sFRP could bind to Wnt and Frizzled (FZD) to destabilize the axin complex and release GSK3ß from the complex, which in turn phosphorylates $ß$-catenin and Tau protein, increases $A ß$ production, and stalls TCF/LEF-initiated transduction of pro-proliferative genes. This could result in the accumulation of Tau and ß-amyloid proteins, and the loss of synaptic integrity and neuronal damage. Dysregulation of the $\mathrm{Wnt} / \mathrm{Ca}^{2+}$ pathway could cause disruption in the N-Methyl-D-aspartate receptors and accumulation of extracellular glutamate. 